Revista Universo Contábil, ISSN 1809-3337

Blumenau, v. 14, n. 2, p. 100-117, abr./jun., 2018

doi:10.4270/ruc.2018213

Disponível em www.furb.br/universocontabil

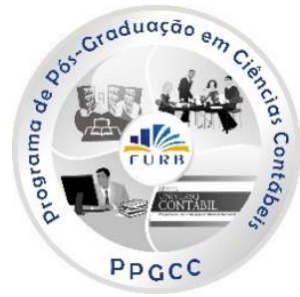

\title{
GERENCIAMENTO DE RESULTADOS EM COMPANHIAS DO SETOR DE CONSTRUÇÃO CIVIL: INFLUÊNCIA DA ADOÇÃO DO CPC $17^{1}$
}

\section{EARNINGS MANAGEMENT IN COMPANIES OF THE CONSTRUCTION SECTOR: INFLUENCE OF CPC 17 ADOPTION}

\section{CONTABILIDAD CREATIVA EN COMPAÑÍAS DEL SECTOR DE CONSTRUCCIÓN CIVIL: INFLUENCIA DE LA ADOPCIÓN DEL CPC 17}

\author{
Juliano Francisco Baldissera \\ Mestrando em Contabilidade pela Universidade Estadual do Oeste do Paraná \\ Endereço: Rua Universitária, 2069 - Jardim Universitário \\ CEP: 85819-110 - Cascavel - PR - Brasil \\ E-mail: juliano.baldissera@hotmail.com \\ Telefone: (45) 3220-3000
}

Adhmir Renan Voltolini Gomes Mestrando em Contabilidade pela Universidade Estadual do Oeste do Paraná Endereço: Rua Universitária, 2069 - Jardim Universitário CEP: 85819-110 - Cascavel - PR - Brasil E-mail: adhmir.renan@gmail.com Telefone: (45) 3220-3000

Aládio Zanchet Doutor em Controladoria e Contabilidade pela Universidade de São Paulo Professor do PPG em Contabilidade da Universidade Estadual do Oeste do Paraná Endereço: Rua Universitária, 2069 - Jardim Universitário CEP: 85819-110 - Cascavel - PR - Brasil E-mail: aladio.unioeste@gmail.com Telefone: (45) 3284-7878

Clovis Fiirst

Mestre em Ciências Contábeis pela Universidade Regional de Blumenau Professor do Departamento de Contabilidade da Universidade Estadual do Oeste do Paraná Endereço: Rua Universitária, 2069 - Jardim Universitário E-mail: cfiirst@gmail.com Telefone: (45) 3220-3000

\footnotetext{
${ }^{1}$ Artigo recebido em 26/10/2017. Revisado por pares em 21/10/2018. Reformulado em 11/12/2018. Recomendado para publicação em 19/12/2018 por Moacir M. Rodrigues Jr. Publicado em 20/02/2019. Organização responsável pelo periódico: FURB.
} 


\section{RESUMO}

No Brasil, a convergência aos padrões contábeis internacionais afetou a realidade das empresas de construção civil, em virtude da adoção do Pronunciamento Técnico CPC 17 - Contratos de Construção, permitindo certa discricionariedade aos preparadores. Diante disso, o objetivo da pesquisa foi verificar o efeito da adoção do CPC 17 no gerenciamento de resultados das empresas brasileiras do setor de construção civil listada na B3 (Brasil Bolsa Balcão). Delineouse esta pesquisa por meio de uma abordagem quantitativa, realizando-se um estudo empírico. A amostra foi composta pelas companhias brasileiras listadas na B3 do setor de construção civil, cujos dados foram coletados por meio da Economática ${ }^{\circledR}$ e da Comissão de Valores Mobiliários (CVM), para o período de 2007 a 2012. Aplicou-se o modelo desenvolvido por Kang e Sivaramakrishnan (1995) para estimar o gerenciamento de resultados. Os dados desta pesquisa demonstraram que no período analisado os níveis de gerenciamento de resultados das empresas do setor de construção civil são decrescentes. Além disso, observou-se que essas empresas gerenciam para baixo os seus resultados, demonstrando que as escolhas contábeis dos gestores não são somente para aumentar seus resultados. Os resultados permitiram concluir que existe diferença significativa nas práticas de gerenciamento antes e depois da vigência da norma, com uma influência negativa do CPC 17 nos níveis de gerenciamento de resultados das empresas. Como contribuição este artigo alerta sobre o possível aumento no gerenciamento de resultados decorrente da adoção do CPC 47 após o primeiro ano.

Palavras-chave: Gerenciamento de Resultados; Contabilidade Imobiliária; Construtoras; Construção Civil; CPC 17.

\section{ABSTRACT}

In Brazil, the convergence to international accounting standards affected the reality of construction companies, due to the adoption of Technical Pronouncement CPC 17 Construction Contracts, allowing some discretion to the preparers. Therefore, the objective of the research was to verify the effect of the adoption of CPC 17 on the earnings management of brazilian companies in the civil construction sector listed on Brasil Bolsa Balcão. This research was delineated by means of a quantitative approach, being carried out an empirical study. The sample was composed by the Brazilian companies listed on the Brasil Bolsa Balcão of the civil construction sector, whose data were collected through Economática ${ }^{\circledR}$ and the Brazilian Securities and Exchange Commission (CVM), for the period from 2007 to 2012. Was applied the model developed by Kang and Sivaramakrishnan (1995) to estimate the earnings management. The data of this research demonstrated that in the analyzed period the earnings management levels of the companies of the civil construction sector are decreasing. In addition, it was observed that these companies manage their results downwards, demonstrating that the managers' accounting choices aren't only to increase their results. The results allow conclude that there is a significant difference in management practices before and after the validity of the standard, and a negative influence of CPC 17 on the results management levels of these companies. As a contribution, this article warns about the possible increase in the earnings management resulting from the CPC 47 adoption after the first year.

Keywords: Earnings Management; Real Estate Accounting; Builders; Construction; CPC 17.

\section{RESUMEN}

En Brasil, la convergencia a los estándares contables internacionales afectó la realidad de las empresas de construcción civil, en virtud de la adopción del Pronunciamiento Técnico CPC 17 - Contratos de Construcción, permitiendo cierta discrecionalidad a los preparadores. Por lo tanto, el objetivo de la investigación fue verificar el efecto de la adopción del CPC 17 en la contabilidad creativa de las empresas brasileñas del sector de construcción civil listadas en la 
Brasil Bolsa Balcão. Se esbozó esta investigación a través de un abordaje cuantitativo, realizándose un estudio empírico. La muestra fue compuesta por las compañías brasileñas listadas en la Brasil Bolsa Balcão del sector de construcción civil, cuyos datos fueron recolectados por medio de la Economática ${ }^{\circledR}$ y de la Comisión de Valores Mobiliarios (CVM), para el período de 2007 a 2012. Se aplicó el modelo desarrollado por Kang y Sivaramakrishnan (1995) para estimar la gestión de resultados. Los datos de esta investigación demostraron que en el período analizado los niveles de contabilidad creativa de las empresas del sector de la construcción civil son decrecientes. Además, se observó que estas empresas gestionan hacia abajo sus resultados, demostrando que las elecciones contables de los gestores no son sólo para aumentar sus resultados. Los resultados permitieron concluir que existe una diferencia significativa en las prácticas de gestión antes y después de la vigencia de la norma, y una influencia negativa del CPC 17 en los niveles de gestión de resultados de estas empresas. Como contribución, este artículo advierte sobre el posible aumento en la gestión de ganancias resultante de la adopción del CPC 47 después del primer año.

Palabras clave: Contabilidad Creativa; Contabilidad Inmobiliaria; Constructoras; Construcción civil; CPC 17.

\section{INTRODUÇÃO}

A informação contábil influencia as decisões individuais de seus usuários, afetando a alocação dos recursos, o funcionamento dos mercados e a eficiência da economia (PAULO, 2007). A demanda por informações contábeis de qualidade se diferencia em razão do tipo de usuários, se externos ou internos, da periodicidade, do volume, do nível de detalhamento e do conteúdo, sendo que no setor de construção civil essas diferenças podem ser ainda mais evidentes, tendo em vista as peculiaridades específicas desse setor (MARCELLI, 2013).

$\mathrm{O}$ reconhecimento das receitas tem sido tema recorrente de discussões no ambiente contábil internacional (FALCÃO; PINTO; NIYAMA, 2014). As particularidades de cada país, a importância do tema para o resultado das empresas e seus desdobramentos financeiros corroboram a necessidade do debate (BECKMAN; KOCZAN, 2006). No cenário brasileiro, a convergência aos padrões contábeis internacionais afetou a realidade das empresas de construção civil, a partir da adoção do Pronunciamento Técnico CPC 17 - Contratos de Construção (correspondente ao Intarnational Accounting Standard - IAS 11, do International Accounting Standard Board - IASB), em 2009. Efeitos serão sentidos também em 2018 quando entrar em vigor o Pronunciamento Técnico CPC 47 - Receita de Contrato com Cliente (correspondente ao Intarnational Financial Reporting Standard-IFRS 15), que substitui, entre outros, o CPC 17.

As novas regras do CPC 17 seguidas pelos preparadores de relatórios contábilfinanceiros estipularam também novas escolhas contábeis que podem ter afetado os níveis de gerenciamento de resultados (JOIA; NAKAO, 2014). As escolhas contábeis podem ser usadas pelos gestores em benefício próprio e, ao mesmo tempo, alinhadas ao interesse da empresa, trazendo ganhos e aumentos de valor para a mesma (JOIA; NAKAO, 2014).

As normas possibilitam certa discricionariedade aos preparadores e, por essa razão, resultados contábeis podem passar a depender do julgamento dos contadores e gestores. Assim, as empresas têm a oportunidade de empregar formas e tipos de manipulação das informações contábeis (MARTINEZ, 2001; COELHO; LOPES, 2007; PAULO, 2007). A convergência dos padrões contábeis locais para as normas do IASB busca reduzir as distorções das informações divulgadas pelas empresas (KLANN, 2011).

Nesse sentido, a flexibilização propiciada pelo CPC 17 nas escolhas dos gestores pode ampliar a margens para a manipulação dos resultados. Visto que o gerenciamento de resultados ocorre quando os gestores utilizam seu poder discricionário e seu julgamento no processo de 
preparação e divulgação de relatórios contábil-financeiros, com objetivo de maximizar o valor da firma, para enganar ou encobrir resultados econômicos não satisfatórios ou com objetivos oportunistas (HEALY; WHALEN, 1999; FIELDS; LYS; VINCENT, 2001). Esse pressuposto é corroborado pela Teoria das Escolhas Contábeis, que entende essas escolhas como qualquer decisão cuja a intenção é influenciar o resultado contábil, não de um modo particular, mas também quando influencia questões externas, como o retorno de impostos e as questões políticas e regulatórias (FIELDS; LYS; VINCENT, 2001).

O setor da construção civil exerce importante papel na economia brasileira, visto que impacta os demais setores e as cadeias produtivas que estão inseridas nas atividades econômicas (MARCELLI, 2013). Esse setor apresenta muita discussão com relação à aplicação de algumas práticas contábeis que foram influenciadas por regulamentações de natureza tributária, o que serviu para afastar a escrituração das melhores práticas contábeis (NIYAMA; CAVALCANTE; REZENDE, 2010).

Diversos estudos, nacionais e internacionais, têm abordado as especificidades desse setor. Questões relacionadas aos critérios de reconhecimento de receitas e de despesas dos contratos de construção (FERREIRA; THEÓPHILO, 2007), à integração dos padrões internacionais IAS 11 e CPC 17 (NASCIMENTO, 2007; NIYAMA; CAVALCANTE; REZENDE, 2010; FIRMINO; ANDRADE, 2015; MOTA; VENTURA; CUNHA; PAULO, 2015) e aos impactos advindos do novo padrão internacional IFRS 15 (DANI; SANTOS; PANUCCI FILHO; KLANN, 2017) são alguns exemplos. Outros estudos já abordaram a discussão sobre a qualidade da informação e do gerenciamento de resultados nas empresas desse setor (ALMEIDA; BEZERRA, 2012; MARCELLI, 2013; LI; CHANG; XIE, 2013; TAO; XU; JI, 2016). Apesar dos avanços já obtidos com esses estudos, percebe-se uma carência de pesquisas que abordem os impactos dos padrões internacionais de contabilidade sobre o gerenciamento de resultados nas empresas do setor de construção civil.

Portanto, considerando os estudos observados e a necessidade de se investigar as práticas de gerenciamento de resultados sob a ótica de determinantes que influenciam essas ações, formulou-se a seguinte pergunta de pesquisa: Quais efeitos a adoção do CPC 17 produziu no gerenciamento de resultados de empresas brasileiras do setor de construção civil listadas na BM\&FBovespa? A partir dessa pergunta, elaborou-se um objetivo geral, que consiste em verificar o efeito da adoção do CPC 17 no gerenciamento de resultados das empresas brasileiras do setor de construção civil listadas na BM\&FBovespa.

Esta pesquisa se justifica pelo fato das discussões empíricas e teóricas sobre a (i) adoção das normas internacionais, bem como do (ii) reconhecimento de receitas e (iii) gerenciamento de resultados, não são discutidas concomitantemente em uma só abordagem. Por isso, além de perceber a carência de estudos que abordam as práticas de gerenciamento de resultados no setor, esta pesquisa busca avançar no desenvolvimento dos estudos sobre a qualidade da informação dessas empresas.

Nesse sentido, a contribuição deste estudo está embasada no sobreaviso referente as possíveis alterações no comportamento dos gestores no quesito de gerenciamento de resultados. Visto que este momento é oportuno, pois ainda não é possível mensurar com profundidade a nova padronização internacional, IFRS 15, que estipulará novas regras e trará novos impactos no reconhecimento de receitas e despesas dessas empresas. Assim, este estudo poderá contribuir para prever o comportamento das empresas no que se refere à adoção do CPC 47. 


\section{REFERENCIAL TEÓRICO}

\subsection{Gerenciamento de Resultados}

O gerenciamento de resultados tem o sentido de intervir de forma intencional na elaboração dos relatórios financeiros externos. Essa intervenção tem o intuito de obter algum ganho particular. Assim, o gerenciamento de resultados está voltado ao gerenciamento das divulgações, pois não abrange relatórios gerenciais e outras atividades que podem influenciar as práticas e os resultados (SCHIPPER, 1989).

Os gestores podem utilizar o seu conhecimento sobre o negócio com o intuito de escolher os métodos de relatórios, estimativas e divulgações correspondente à situação econômica desejada. Assim, a divulgação tem o potencial de manusear o valor da contábil como ferramenta de comunicação. Visto que a auditoria é imperfeita, o juízo da administração dá oportunidades para o gerenciamento de resultados. Ou seja, os gestores podem escolher os métodos ou as estimativas que não refletem com precisão a situação econômica daquela organização (HEALY; WAHLEN, 1999).

As normas contábeis admitem que os gestores realizem escolhas gerenciais para aplicar métodos contábeis para divulgar o desempenho da empresa. Porém, quando essas escolhas são utilizadas com a intenção de manipular os resultados divulgados, são caracterizadas como gerenciamento de resultados (RICHARDSON, 2000). O gerenciamento de resultados evidencia o problema de agência, pois os proprietários ou gerentes podem utilizar do controle com intuito de se beneficiar dos demais stakeholders (LEUZ; NANDA; WYSOCKI, 2003).

Mesmo que as escolhas de relatórios financeiros possam violar os princípios contábeis geralmente aceitos e constituir-se em fraude, o gerenciamento de resultados pode ocorrer dentro dos limites dos princípios contábeis geralmente aceitos (DECHOW; SKINNER, 2000). Assim, é de suma importância compreender que o gerenciamento de resultados não é uma fraude contábil, pois as escolhas dos gerentes ocorrem dentro dos limites estabelecidos nos padrões contábeis, o que justifica o estudo sob a ótica da Teoria das Escolhas Contábeis. Quando a norma faculta a discricionariedade para os gerentes, esses optam por escolhas que não necessariamente refletem a realidade econômica. Ou seja, os gerentes podem optar em função dos benefícios que terão ao reportar determinado resultado (MARTINEZ, 2001).

As definições de gerenciamento de resultados concentram-se nas intenções gerenciais, que, por sua vez, são inobserváveis. Com isso, torna-se difícil operacionalizar um modelo matemático atribuindo apenas números contábeis relatados (DECHOW; SKINNER, 2000). Entre as preocupações referente aos procedimentos metodológicos nos estudos empíricos sobre a discricionariedade nos accruals está a determinação das variáveis que são as mais úteis para predizer os componentes não gerenciados. Entretanto, os números contábeis provavelmente são afetados pelo gerenciamento dos resultados (KANG; SIVARAMAKRISHNAN, 1995).

Nesse sentido, os accruals são definidos como acumulações representadas pela discrepância entre o lucro líquido e o fluxo de caixa operacional líquido. Logo, são todas as classificações de resultados que são computadas ao lucro e que não provoquem movimentações de caixa e ou de equivalentes de caixa. A finalidade dos accruals é representar o lucro de forma econômica, ou seja, é representar de forma efetiva a riqueza agregada em unidade econômica ao patrimônio da empresa.

Contudo, existe o fato do gestor poder tomar a decisões de modo que influencie a discricionariedade, aumentando ou diminuindo os accruals. Assim, o gestor pode manipular o lucro por razões discrepantes ao negócio. Os accruals podem ser tanto discricionários quanto não discricionários. A diferença entre eles é que os não discricionários têm o intuito de gerir os resultados contábeis, enquanto os discricionários se referem a uma proxy do gerenciamento de resultados (MARTINEZ, 2008). 


\subsection{Reconhecimento de Receita em Contratos de Construção}

O reconhecimento de receita em empresas que operam com contratos de construção civil, assim como as demais empresas, tende a ser feita em atendimento pleno ao Regime de Competência, o qual determina que as receitas e as despesas devem ser registradas quando ocorrer eventos econômicos que as determinem, e não nos momentos em que os valores são recebidos ou desembolsados. Entretanto, existe dificuldade na contabilização dessas operações visto que o ciclo operacional de uma construtora é maior que exercício social (BARBOSA; SOUZA; DALFIOR, 2015).

A contabilidade na construção civil sempre teve dificuldades com relação aos critérios utilizados para contabilização das receitas e despesas, dado que, muitas vezes, não conseguem expressar de forma fiel a situação financeira em suas demonstrações (CALAZANS; SOUZA, 2012).

O CPC 17 estabelece a forma como devem ser reconhecidos ou mensurados e também como devem ser contabilizados os resultados no ramo da construção civil, sendo que no ato da elaboração das demonstrações, ao encerrar um exercício, há dificuldades em atribuir as devidas proporções de receitas e despesas, uma vez que as receitas demonstradas se referem a um componente em fase de elaboração.

Diante disso, de acordo com o CPC 17 para os contratos de construção por empreitada, utiliza-se um conceito de longo prazo, superior a doze meses, e contratos de curto prazo de até doze meses. Nos de longo prazo, o reconhecimento das receitas ocorre com o andamento da obra; enquanto no de curto prazo, apenas ao final da obra, que também pode gerar certa inconsistência contábil nos registros das empresas de construção (BARBOSA; SOUZA; DALFIOR, 2015).

Diante disso, a mensuração da receita pode ser afetada por incertezas que dependem do desfecho nos acontecimentos futuros da construção (MARTíNEZ, 2011). Nas receitas de contratos, variações são incluídas quando for provável que o cliente aprovará a variação e o valor cobrado, e a quantia da receita puder ser mensurada com confiança. Essa variação pode ter um aumento ou a uma diminuição na receita (BARLEV; HADDAD, 2003).

Entra em vigor, no exercício social com início em 2018, o novo Pronunciamento Técnico CPC $\mathrm{n}^{\circ} 47$, espelhado na IFRS $\mathrm{n}^{\circ} 15$. O reconhecimento de receita de contratos com clientes passa a ter uma nova disciplina normativa, baseada na transferência do controle de um bem ou serviço, seja essa transferência observada em um momento específico ("at a point in time"), seja essa transferência observada ao longo do tempo ("over time"), conforme a satisfação ou não das denominadas "obrigações de performance" contratuais.

\subsection{Estudos Anteriores}

O estudo de Ferreira e Theóphilo (2007) abordou o conhecimento sobre Contabilidade nas empresas de construção civil, no que tange aos aspectos de reconhecimento de receitas e de despesas. Para isso, foi reunido estudos dos conceitos teóricos sobre a Contabilidade de empresas do setor e foram observados os princípios, normas e práticas contábeis, e ainda, foi abordado aspectos da legislação tributária brasileira, com o intuito de comparar com a prática realizada por uma empresa desse segmento. Os achados demonstraram uma melhora pertinente no potencial informativo das demonstrações contábeis após a reformulação inerente à adoção das concepções voltadas a refletir a essência da posição econômica e financeira.

Já Nascimento (2007) teve como objetivo identificar as práticas contábeis nas empresas de construção civil na apropriação de receitas e de custos, com vistas a visualizar a aderência aos procedimentos internacionalmente aceitos para essa atividade econômica. Em seus achados, verificou-se que as empresas brasileiras do setor de construção civil não possuem aderência total às normas contábeis provenientes do IASB, IBRACON e CFC, pois esse fato decorre em 
virtude normatização fiscal divergente. Todavia, existe as atividades referente às construções pesadas que aproximam-se mais das normas fiscais, pois existem maior aderência e harmonia entre as normas e os aspectos fiscais existente, o que não é valido para os empreendimentos imobiliários.

As distorções provocadas no financial reporting de uma empresa do ramo de construção civil no que se refere aos critérios de construção civil para reconhecimento de receitas e despesas, segundo as normas brasileiras, norte-americanas e internacionais de contabilidade, foram objeto de estudo de Niyama, Cavalcante e Rezende (2010). Em seus resultados, demonstraram que as diferentes formas de reconhecimentos de receitas e despesas frente às normas brasileiras, norte americanas e internacionais apresentam distorções nos relatórios financeiros. Em evidência estão os contratos de compra e venda, tanto a prazo quanto à vista de unidades não concluídas.

A influência do fluxo de caixa operacional na identificação do gerenciamento de resultados em empresas da construção civil foi objeto de estudo de Almeida e Bezerra (2012). Nesse estudo, foi possível identificar a existência da prática de gerenciamento de resultados no segmento de construção civil, em todos os períodos, contudo, o ano de 2009 ficou em evidência, pois foi o ano que mais se gerenciaram os resultados.

No que tange ao gerenciamento de resultados, Marcelli (2013) investigou a existência de evidências de práticas de gerenciamento de resultados nos dados divulgados pelas construtoras brasileiras. Nos achados, foi evidenciado que as demonstrações financeiras publicadas pelas construtoras entre os anos de 2003 a 2006 e nos anos de 2009 e 2010 apresentaram indícios de gerenciamento de resultados. Nesses anos foi utilizada a variável receita líquida dos imóveis vendidos. E ainda, os achados demonstraram que as construtoras de maior porte tendiam a gerenciar os resultados mais que as construtoras de menor porte. As informações necessárias para avaliar a qualidade e o desempenho das companhias não eram divulgadas, assim sendo, o estudo apontou para a necessidade de uma reforma nas políticas de divulgação das demonstrações financeiras.

No âmbito internacional, Li, Chang e Xie (2013) analisaram as práticas de gerenciamento de resultados em empresas do setor de construção civil na China. O estudo demonstrou que as empresas de construção geralmente ajustam seus ganhos de forma negativa, com finalidade de reduzir o desempenho das empresas, e controlar tanto os dividendos e o planejamento tributário.

Com relação à adoção de normas internacionais de contabilidade aos contratos de construção, o estudo de Firmino e Andrade (2015) demonstrou que, após a adoção das IFRS, houve aumento nos valores dos patrimônio líquido, receita e resultado do período. Todavia, por meio de teste de Wilcoxon, os valores do patrimônio líquido, receitas e resultados das empresas de construção civil não sofreram variações estatisticamente significantes.

Nessa mesma linha de pesquisa, Mota et al. (2015) analisaram quais as normas provenientes da adoção da IFRS pelo Brasil causaram alterações no Balanço Patrimonial das empresas do setor de construção civil. Em seus achados, observou-se variações na estrutura patrimonial, sendo estas no ativo total, passível exigível e patrimônio líquido. Todavia, com o teste de Wilcoxon, as variações não se demonstraram estatisticamente significantes. Assim, entre as normas que mais implicaram modificações no balanço patrimonial destacam-se: a segregação dos impostos diferidos, reconhecimento de valores em juízo e depósitos judiciais e reconhecimento das permutas.

Já Xu e Ji (2016) analisaram os comportamentos de gerenciamento de resultados, com base no regime de competência e no fluxo de caixa, das empresas chinesas durante a crise financeira global, no tocante ao segmento de construção civil e de aviação. Nos achados, as empresas chinesas incluíram o gerenciamento de resultados no que tange à construção civil. A direção do gerenciamento de resultados demonstrou que empresas das indústrias relacionadas 
a construção manipularam os lucros para cima por meio de atividades baseadas accruals ou fluxos de caixa. Os resultados refletem o estímulo do governo chinês para combater a crise financeira global.

Já voltados para à adoção das IFRS 15, Dani et al. (2017) associaram o ganho informacional à redução no conservadorismo, que é propiciado à adoção do padrão internacional, IFRS 15, pois nesta o valor justo gera números mais próximos da realidade diminuindo o viés e permite, assim, deixar o lucro mais próximo da realidade econômica, que por consequência, contribui aumentando a relevância das informações para os usuários.

\section{METODOLOGIA}

Para obter uma resposta ao problema de pesquisa e atingir aos objetivos propostos, utilizou-se de uma abordagem quantitativa, por meio de um estudo empírico, com o emprego de instrumentos estatísticos no tratamento dos dados.

Aplicou-se o modelo desenvolvido por Kang e Sivaramakrishnan (1995) para estimar o gerenciamento de resultados. Primeiro, verificou-se o comportamento de gerenciamento de resultados dessas empresas, analisando-se tanto o modo como a intensidade dessas práticas de gerenciamento contábil e, em seguida, investigou-se se a adoção do CPC 17 influenciou mudanças nos níveis de gerenciamento de resultados.

Devido aos problemas metodológicos dos modelos de accruals discricionários de acumulações totais, que vão desde erros de mensuração, omissão de variáveis até inferências errôneas, Kang e Sivaramakrishnan (1995) propuseram a inclusão de variáveis explicativas provenientes de contas contábeis.

Assim, o modelo representa as diferentes contas patrimoniais e de resultado das demonstrações contábeis, tratando das principais contas das demonstrações contábeis para captar o efeito discricionário e não discricionário das escolhas contábeis, com o intuito de minimizar problemas de variáveis omitidas, por trabalhar com as variações para aferir os accruals discricionários. Contudo, dentre as variáveis utilizadas estão as instrumentais, para controlar o ambiente econômico, as quais podem também ser contaminadas pelo gerenciamento de resultados. Assim, para analisar o gerenciamento de resultados foi utilizado neste estudo o modelo proposto por Kang e Sivaramakrishnan K-S (1995) para todo o período analisado. Os accruals não discricionários são estimados por meio da regressão descrita na Equação 1.

$$
\frac{A B_{i t}}{A t_{i t-1}}=\beta_{0}+\beta_{1}\left(\frac{\delta_{1} \operatorname{Rec}_{i t}}{A t_{i t-1}}\right)+\beta_{2}\left(\frac{\delta_{2} D_{i t}}{A t_{i t-1}}\right)+\beta_{3}\left(\frac{\delta_{3} P P E_{i t}}{A t_{i t-1}}\right)+\varepsilon_{i t}
$$

Em que:

$A B_{i t}=$ accruals balance da empresa i no período $\mathrm{t}$, ponderados pelos ativos totais no final do período t-1;

$A B_{i t}=C R+I N V+O C A-C L-$ Deprec $\mathrm{e}$

$C R=$ contas a receber da empresa i no período t;

$I N V=$ estoques da empresa i no período $\mathrm{t}$;

$O C A=$ outros ativos circulantes excluindo caixa, contas a receber e estoques no período t;

$C L=$ passivo circulante excluindo impostos a pagar e parcelas de dívidas de longo prazo no circulante no período $t$;

Deprec $=$ depreciação da empresa i no período $\mathrm{t}$;

$A t_{i t}=$ ativos totais da empresa i no período t;

$R e c_{i t}=$ receitas líquidas da empresa i no período t;

$D_{i t}=$ despesas operacionais antes da empresa i no período $\mathrm{t}$;

$P P E_{i t}=$ ativo Imobilizado empresa i no período t; 
E os parâmetros de especificidade das empresas são representados da seguinte forma:

$\delta_{1}=$ refere-se ao quociente de $\frac{C R_{i, t-1}}{R e c_{i t-1}} \mathrm{e}$;

$\delta_{2}=$ refere-se ao quociente de $\frac{I N V_{i, t-1}+O C A_{i, t-1}+C L_{i, t-1}}{D_{i, t-1}} \mathrm{e}$;

$\delta_{3}=$ refere-se ao quociente de $\frac{\text { Depr }_{i, t-1}}{P P E_{i, t 1}}$

$\beta_{0}, \beta_{1}, \beta_{2}, \beta_{3}=$ coeficientes linear e angulares

$\varepsilon_{i t}=$ resíduos da regressão da empresa i no período t;

A amostra deste estudo corresponde às companhias abertas do setor de construção civil listadas na BM\&FBOVESPA, assim como é classificado na Economática ${ }^{\circledR}$. Inicialmente, obteve-se 41 empresas, após retirar as empresas com dados faltando, a quantidade de empresas que compôs a amostra foi igual a 29. Todas as empresas tinham contratos de receita de longo prazo, mas nem todas as receitas eram derivadas da atividade principal dessa empresa, o que representa uma limitação, uma vez que não é possível restringer só a esses casos.

Quanto ao período, foi referente aos anos de 2007 a 2012, devido à vigência do CPC 17. Não selecionou-se um período maior, devido a limitação na quantidade de empresas, uma vez que muitas não estão presentes em todo o período até 2017. A escolha deste setor se deu pelo fato de que ele exerce importante papel na economia do país e também impacta nos demais setores e em suas cadeias produtivas (MARCELLI, 2013). Ademais, tem-se muita discussão no que tange à aplicação das práticas contábeis advindas por regulamentações de natureza tributária, o, que por sua vez, pode afastar a efetivação das melhores práticas contábeis (NIYAMA; CAVALCANTE; REZENDE, 2010).

Primeiramente, realizou-se o teste de Mann-Whitney para inferir os níveis dos accruals discricionários médios antes e após a adoção do CPC 17 pelas empresas do setor de construção civil. Na sequência, foi realizada uma regressão múltipla com uma variável dummy para identificar o efeito do CPC 17 na acumulação discricionária (resíduos da regressão referente ao modelo K-S), das qual se espera uma associação significativa, não sendo possível afirmar em qual sentido devido a literatura anterior ainda não ter confirmado. Além da variável dependente e dummy, a equação 2 descreve as variáveis de controles utilizadas, já confirmada na literatura anterior (JOIA; NAKAO, 2014).

$$
G r_{i t}=\beta_{0}+\beta_{1} E N D_{i t}+\beta_{2} R O A_{i t}+\beta_{3} F C O_{i t}+\beta_{4} T A M_{i t}+\beta_{5} C P C_{i t}+\varepsilon_{i t}
$$

Em que:

$G r_{i t}$ é o gerenciamento de resultado (Resíduos da regressão K-S) das empresas empresa i no período t;

$C P C_{i t}$ variável dummy referente ao período do CPC 17, 0 para antes e 1 para depois.

E as variáveis de controle são:

$E N D_{i t}$ é o endividamento da empresa i no período t;

$R O A_{i t}$ é o retorno sobre o ativo da empresa i no período t;

$F C O_{i t}$ é o fluxo de caixa operacional da empresa i no período t;

$T A M_{i t}$ é o tamanho da empresa da empresa i no período t;

Dessa forma, este estudo foi realizado por meio da abordagem de pesquisa quantitativa, que caracteriza-se pelo emprego de coleta e tratamento de informações por meio de técnicas estatísticas, desde as mais simplórias, como média, desvio padrão, até as mais complexas como regressão múltipla (RICHARDSON, 1999). Quanto à coleta de dados, foi realizada por meio de dados secundários, pois as contas contábeis usadas neste estudo foram coletadas por fonte 
privada, Economática ${ }^{\circledR}$. O método utilizado para a análise foi a combinação de corte transversal com séries temporais, denominado dados em painel, com auxílio do software STATA ${ }^{\circledR}$.

\section{ANÁLISE E DISCUSSÃO DOS RESULTADOS}

Inicialmente, realizou-se o teste para verificar se o comportamento das empresas do setor de construção civil brasileiro, no que se refere aos níveis de gerenciamento de resultados, foi decrescente depois da vigência do CPC 17. A Tabela 1 evidencia o comportamento médio do gerenciamento de resultados proporcionado pelo modelo KS (Equação 1) no período entre 2007 e 2012, que se refere ao momento anterior e posterior ao CPC 17.

Tabela 1 - Resultado do Modelo KS para o Período Anterior e Posterior à Vigência do CPC 17

\begin{tabular}{|c|c|c|c|c|c|c|}
\hline \multirow{2}{*}{$\begin{array}{l}\text { Gerenciamento de } \\
\text { Resultados }\end{array}$} & \multicolumn{3}{|c|}{ Antes CPC 17} & \multicolumn{3}{|c|}{ Depois CPC 17} \\
\hline & 2007 & 2008 & 2009 & 2010 & 2011 & 2012 \\
\hline $\begin{array}{l}\text { Média dos Accruals } \\
\text { Discricionários }(\varepsilon) \\
\text { Positivos }\end{array}$ & 0,47 & 0,27 & 0,13 & 0,19 & 0,10 & 0,09 \\
\hline $\begin{array}{c}\text { Média dos Accruals } \\
\text { Discricionários }(\varepsilon) \\
\text { Negativos }\end{array}$ & $-0,44$ & $-0,22$ & $-0,19$ & $-0,13$ & $-0,11$ & $-0,09$ \\
\hline $\begin{array}{l}\text { Média dos Accruals } \\
\text { Discricionários }(\varepsilon) \text { em } \\
\text { valores absolutos }\end{array}$ & 0,52 & 0,30 & 0,21 & 0,21 & 0,16 & 0,17 \\
\hline \multicolumn{7}{|c|}{ Regressão Linear Múltipla - Modelo KS } \\
\hline Variáveis & $\begin{array}{l}\text { Coef. } \\
\text { (sig.) }\end{array}$ & $\begin{array}{l}\text { Coef. } \\
\text { (sig.) }\end{array}$ & $\begin{array}{l}\text { Coef. } \\
\text { (sig.) }\end{array}$ & $\begin{array}{l}\text { Coef. } \\
\text { (sig.) }\end{array}$ & $\begin{array}{l}\text { Coef. } \\
\text { (sig.) }\end{array}$ & $\begin{array}{l}\text { Coef. } \\
\text { (sig.) }\end{array}$ \\
\hline & 1,053 & 1,084 & 0,13 & 0,696 & 0,708 & 00,705 \\
\hline$\beta 1$ & $(0,004)$ & $(0,002)$ & $(0,017)$ & $(0,000)$ & $(0,000)$ & $(0,000)$ \\
\hline R2 & $-0,113$ & 0,364 & 0,653 & 0,736 & 0,598 & 0,744 \\
\hline$\beta 2$ & $(0,303)$ & $(0,007)$ & $(0,000)$ & $(0,000)$ & $(0,002)$ & $(0,000)$ \\
\hline & 0,400 & 0,251 & 00,584 & $-5,228$ & $-1,779$ & $-5,989$ \\
\hline$\beta 3$ & $(0,010)$ & $(0,842)$ & $(0,863)$ & $(0,005)$ & $(0,686)$ & $(0,102)$ \\
\hline & 0,515 & 0,121 & 0,287 & 0,179 & 0,133 & 0,16 \\
\hline (Constante) & $(0,003)$ & $(0,329)$ & $(0,001)$ & $(0,033)$ & $(0,050)$ & $(0,004)$ \\
\hline $\mathbf{R}^{2}$ & 0,305 & 0,394 & 0,505 & 0,627 & 0,635 & 0,729 \\
\hline F significance & 0,007 & 0,001 & 0,000 & 0,000 & 00,000 & 0,000 \\
\hline Durbin-Watson & 1,857 & 2,248 & 1,830 & 2,221 & 2,186 & 1,861 \\
\hline Mean VIF & 1,200 & 1,004 & 1,166 & 1,111 & 1,109 & 1,063 \\
\hline $\mathbf{N}$ & 29 & 29 & 29 & 29 & 29 & 29 \\
\hline
\end{tabular}

*** Significância ao nível de 0,01 - ** Significância ao nível de 0,05- * Significância ao nível de 0,10Fonte: Elaborada pelos pesquisadores (2017).

Observa-se na Tabela 1 que a modelagem estatística utilizada a fim de verificar o nível de gerenciamento de resultado mostra-se consistente, uma vez que o modelo, composto de 174 observações, apresenta-se significante ao nível de $1 \%$. $\mathrm{O} \mathrm{R}^{2}$, sendo esse o poder explicativo, que representa a proporção da variação amostral da variável dependente explicada pelas variáveis explicativas (Wooldridge, 2003), o menor foi 30,5\% e o maior foi 72,9\%, o que pode ser considerado relevante. Além disso, o Durbin-Watson encontra-se dentro do limite de aceitação, uma vez que está próximo de 2 em todas as situações. Além de não haver problemas de multicolinearidade, conforme aponta teste VIF (Fator de Inflação de Variância).

Comparando-se o comportamento do gerenciamento em valores negativos e positivos, percebe-se que as empresas do setor de construção civil estão diminuindo o nível de gerenciamento, uma vez que observa-se os accruals diminuindo e chegando próximo a zero. A redução mais acentuada foi entre o período de 2007 a 2008. Apesar de haver um aumento nos 
níveis de gerenciamento de resultados positivo no período de 2009 a 2010, nota-se que houve reduções sucessivas.

As diferentes formas de reconhecimento e de receita e despesa, seja pelo regime de competência ou pelo regime de caixa, considerando a discricionariedade existente neste setor, frente às normas nacionais e internacionais, apresentam distorções nos relatórios financeiros, conforme é evidenciado no estudo de Niyama, Cavalcante e Rezende (2010). A qualidade da informação contábil é comprometida nas empresas do setor de construção civil, percebendo-se que essas empresas têm divulgado seu desempenho de forma negativa, confirmando-se o que é estabelecido por Healy (1985), isto é, o resultado não é gerenciado somente para melhorar os resultados, mas também para reduzi-los.

Esse resultado também se aproxima ao observado no estudo de Silva (2009), em que buscou identificar e analisar os valores de gerenciamento de resultados nas Companhias Abertas e Fechadas da região Sul do Brasil por segmentos econômicos especificados pela BM\&FBovespa. Silva (2009) observou que no setor de construção civil uma disparidade entre os níveis de gerenciamento de resultados, ora sendo negativos para algumas empresas em determinados períodos, ora positivos. Os resultados apresentados na Tabela 1, conforme as médias obtidas pelos accruals discricionários, demonstram variar entre positivos, em $2007 \mathrm{e}$ 2008, e negativos, em 2009 a 2012.

No estudo de Xu e Ji (2016), analisando o comportamento das empresas chinesas no período de crise financeira global, observou-se que o gerenciamento das empresas relacionadas à construção era positivo. No entanto, Li, Chang e Xie (2013) analisaram as empresas do setor de construção civil da China, sem considerar um período em especial; observaram que essas empresas também ajustavam seus resultados de forma negativa, o que corrobora as evidências das empresas brasileiras. Uma das justificativas trazidas pelos autores, e que pode explicar essa constatação deste setor no Brasil, é que as empresas reduzem seu desempenho para controlar tanto os dividendos quanto o planejamento tributário para fins fiscais.

Em uma segunda análise, com o objetivo de verificar os níveis de gerenciamento de resultados, calculou-se os resíduos da regressão (accruals discricionários) em valores absolutos, o que permite inferir a respeito dos níveis de gerenciamento nessas empresas, sejam eles positivos ou negativos. A análise dos resíduos em valores absolutos é importante para verificar a qualidade da informação contábil (KRISHNAN, 2003), sendo inclusive normalmente utilizado em estudos nacionais (ALMEIDA; ALMEIDA, 2009).

É possível inferir que os níveis de gerenciamento reduzem ao longo do período analisado, o que demonstra que as escolhas contábeis feitas pelas empresas dessa amostra reduziram o grau de gerenciamento de resultados depois da vigência do CPC 17, o que sugere que essa norma reduziu o nível de gerenciamento de resultados nas empresas desse setor. A maior redução pode ser observada de 2007 a 2008.

O estudo de Klann (2011) observou que as empresas brasileiras, em um contexto geral, aumentaram os níveis de gerenciamento de resultados no período de pós-convergência às normas internacionais do IASB. Apesar disso, os resultados apresentados na Tabela 1 corroboram os achados de Joia e Nakao (2014), que observaram uma redução nos níveis de gerenciamento após a adoção das normas internacionais de contabilidade pelas empresas brasileiras, ainda que eles não tivessem demonstrado significância estatística.

Assim, as normas internacionais, bem como o próprio CPC 17, melhoraram o potencial informativo das demonstrações contábeis após a reformulação das normas contábeis, as quais buscavam refletir melhor a essência da posição econômica e financeira, conforme evidenciam Ferreira e Theóphilo (2007).

Especificamente, nas empresas do setor de construção civil, assim como os estudos de Silva (2009), Almeida e Bezerra (2012), Li, Chang e Xie (2013), Marcelli (2013) e Xu e Ji (2016), percebeu-se a existência de gerenciamento de resultados. Almeida e Bezerra (2012) 
analisaram o período de 2007 a 2009 e constataram que o ano de maior gerenciamento foi o de 2009 , contrariando o resultado desta pesquisa, a qual destacou o ano de 2007; isso talvez se deva ao modelo de mensuração utilizado para os accruals discricionários. Marcelli (2013) também observou indícios de gerenciamento de resultados, principalmente, nos anos de 2009 e 2010, além de terem percebido que as construtoras de maior porte gerenciam mais que as construtoras menores.

Como o objetivo do trabalho é ir além de analisar os níveis de gerenciamento de resultados das empresas deste setor, mas buscar fomentar a discussão e preencher a lacuna de pesquisas no que se refere à contribuição da adoção das normas internacionais na redução dos níveis de gerenciamento de resultados destas empresas, parte-se então para o Teste de Diferença de Médias (Tabela 2) e da regressão linear múltipla (Tabela 3) para confirmar estatisticamente a influência do CPC 17 na redução dos níveis de gerenciamento das companhias abertas brasileiras do setor de construção civil.

Tabela 2 - Teste U de Mann-Whitney entre GR e CPC 17

\begin{tabular}{|c|c|c|c|}
\hline & Média antes CPC 17 & Média depois do CPC 17 & $\mathbf{Z}$ \\
\hline GR & 0,2899 & 0,1185 & $4.977 * * *$ \\
\hline
\end{tabular}

O Teste U de Mann-Whitney permite inferir que os níveis dos accruals discricionários médios, em valores absolutos, foram reduzidos de forma estatisticamente significativa após a adoção do CPC 17 pelas empresas do setor de construção civil. Assim, é possível confirmar que a aderência às normas internacionais, como também especificamente ao CPC 17, impacta o reconhecimento de receitas e despesas do setor de construção civil, com redução do nível de gerenciamento de resultados, já que o teste de diferença de média para os grupos foi significante ao nível de $1 \%$.

Para analisar o impacto do evento da adoção do CPC 17 sobre o gerenciamento de resultados, realizou-se o cálculo do modelo proposto na Equação 2, que se trata de uma regressão linear múltipla com dados em painel. Os resultados da regressão, bem como os pressupostos do modelo, foram evidenciados na Tabela 4.

Tabela 3 - A influência do CPC 17 nos níveis de Gerenciamento de Resultados das Empresas do Setor de Construção Civil

\begin{tabular}{|c|c|c|c|c|c|c|c|c|c|c|c|}
\hline \multirow{2}{*}{$\begin{array}{c}\text { Prob }>\text { F } \\
0.0000\end{array}$} & $\mathbf{R}^{2}$ & VIF & \multicolumn{2}{|c|}{ DW } & $\begin{array}{c}\text { Teste } \\
\text { BP/CW }\end{array}$ & $\begin{array}{l}\text { Teste } \\
\text { White } \\
\end{array}$ & $\begin{array}{l}\text { Teste } \\
\text { B e P }\end{array}$ & $\begin{array}{c}\text { F de } \\
\text { Chow }\end{array}$ & \multicolumn{2}{|c|}{$\begin{array}{c}\text { Teste } \\
\text { Hausman }\end{array}$} & $\begin{array}{l}\mathbf{N}^{\mathbf{2}} \\
\text { Obs }\end{array}$ \\
\hline & 0.1665 & 1.24 & & 3646 & 0.0000 & 0.0076 & 1.0000 & 0.5199 & & & 174 \\
\hline \multirow{2}{*}{\multicolumn{2}{|c|}{ Variáveis Indep. }} & \multicolumn{10}{|c|}{ Painel com Efeitos POLS } \\
\hline & & \multicolumn{2}{|c|}{ Coeficiente } & \multicolumn{2}{|c|}{$\begin{array}{c}\text { Erro } \\
\text { Padrão } \\
\end{array}$} & $T$ & P-Value & \multicolumn{4}{|c|}{ Interv. Conf. 95\% } \\
\hline \multicolumn{2}{|c|}{ CPC17 } & \multicolumn{2}{|c|}{-.1659837} & \multicolumn{2}{|c|}{.0282575} & -5.87 & $0.000 * * *$ & \multicolumn{2}{|c|}{-.2217692} & \multicolumn{2}{|c|}{-.1101981} \\
\hline \multicolumn{2}{|c|}{ END } & \multicolumn{2}{|c|}{-.0061509} & \multicolumn{2}{|c|}{.0605648} & -0.10 & 0.919 & \multicolumn{2}{|c|}{-.1257171} & \multicolumn{2}{|c|}{.1134154} \\
\hline \multicolumn{2}{|c|}{ ROA } & \multicolumn{2}{|c|}{-.3528557} & \multicolumn{2}{|c|}{.1872548} & -1.88 & $0.061 *$ & \multicolumn{2}{|c|}{-.7225315} & \multicolumn{2}{|c|}{.01682} \\
\hline \multicolumn{2}{|c|}{ FCO } & \multicolumn{2}{|c|}{$-1.39 \mathrm{e}-08$} & \multicolumn{2}{|c|}{$4.79 \mathrm{e}-08$} & -0.29 & 0.772 & \multicolumn{2}{|c|}{$-1.08 \mathrm{e}-07$} & \multicolumn{2}{|c|}{$8.06 \mathrm{e}-08$} \\
\hline \multicolumn{2}{|c|}{ TAM } & \multicolumn{2}{|c|}{-.0031412} & \multicolumn{2}{|c|}{.0045214} & -0.69 & 0.488 & -.012 & 673 & .00 & 7849 \\
\hline _cc & & .33695 & & .0778 & 208 & 4.33 & $0.000 * * *$ & .1833 & & .49 & 5893 \\
\hline
\end{tabular}

Fonte: Elaborada pelos pesquisadores (2017).

Os resultados dos testes Breusch-Pagan (1,0000), F de Chow (0.5199) e Hausman (0.1472), indicam que a modelagem apropriada para análise da amostra estudada com dados 
em painel é de efeitos POLS, pois o teste de Breusch-Pagan apresentou-se maior que 0,05, o que consequentemente levou-se a verificar o teste de Chow, que se sinalizou maior que 0,05 .

Observa-se na Tabela 4 que a modelagem utilizada a fim de verificar a influência do CPC 17 sobre os níveis de gerenciamento de resultados das empresas do setor de construção civil (Equação 2) mostra-se consistente, uma vez que o modelo composto por 174 observações se apresenta significante ao nível de $1 \%$. O R ${ }^{2}$, sendo este o poder explicativo do modelo, é de 16,65\%. As variáveis independentes CPC 17, ROA e TAM são capazes de explicar a dependente (GR). O modelo não apresenta problemas de autocorrelação, uma vez que o DurbinWatson é de 1,533646, além de não haver problemas de multicolinearidade, conforme aponta o teste VIF $(1,24)$. O teste de Breusch-Pagan/Cook-Weisberg $(0,0000)$ e o teste de White $(0,0076)$ indicam ter problemas de heterocedasticidade nos resíduos. Por isso, para confiabilidade e robustez, aplicou-se a correção robusta de White.

A partir dos resultados da regressão, é possível perceber que a adoção do CPC 17 influenciou negativamente os níveis de gerenciamento de resultados, considerando um nível de $1 \%$ de significância. Essa constatação sugere que a norma serviu como um mecanismo de contra incentivo ao gerenciamento de resultados das empresas do setor de construção civil. Esse resultado corrobora com as análises anteriores, em que se verificou o comportamento médio dos accruals discricionários e o teste de diferença de médias.

Esse resultado confirma alguns estudos (BARTH; LANDSMAN; LANG, 2008; JEANJEAN; STOLOWY, 2008; IATRIDIS, 2010; IATRIDIS; ROUVOLIS, 2010; BONFIM; SILVA; GONÇALVES; SILVA, 2016) e contrasta aos achados de outros que não encontraram relação entre a redução do gerenciamento de resultados com a adoção de padrões internacionais (TENDELOO; VANSTRAELEN, 2005; ELBANNAN, 2011; JOIA; NAKAO, 2013). Ainda que estes estudos anteriores não testaram a mesma relação, são considerados marginais e abordam um contexto semelhante, o que justifica a comparação. Essa pesquisa avança com a discussão dos estudos anteriores a respeito deste tema, bem como prepara o assunto para a nova norma (IFRS 15) que impactará o reconhecimento de receitas e despesas das empresas deste setor.

Os estudos de Firmino e Andrade (2015) e Mota et al. (2015) analisaram o impacto da adoção de normas internacionais nas contas patrimoniais e resultado do balanço patrimonial das empresas do setor de construção civil, os resultados sugeriam não haver diferença estatisticamente significativa. Apesar desse resultado, os resultados apontados pela Tabela 4 indicam que o CPC 17 influenciou o nível de gerenciamento de resultados destas empresas, a qual é calculado diretamente por diversas contas contábeis, conforme se apresentou na Equação 1.

Tendeloo e Vanstraelen (2005) concluíram que não há diferença no GR entre as empresas que divulgam em IFRS e no padrão de divulgação da Alemanha. Elbannan (2011) encontrou um resultado não significativo ao analisar se as empresas do Egito tiveram seus índices de GR reduzidos após a adoção do IAS. Joia e Nakao (2013) não confirmaram a hipótese de que a adoção de IFRS afetou o nível de gerenciamento de resultados das empresas brasileiras no período de 2006 a 2011. Portanto, percebe-se que, ao verificar as características específicas do cenário brasileiro das empresas do setor de construção civil, os resultados são diferentes, demonstrando uma relação significativa entre a redução do GR e a adoção do CPC 17.

Barth, Landsman e Lang (2008) observaram que a aplicação das normas internacionais está associada a um menor GR em uma amostra de 21 países, representando uma melhoria na qualidade da informação contábil. Iatridis (2010), em empresas do Reino Unido, Iatridis e Rouvolis (2010), em empresas da Grécia, e Jeanjean e Stolowy (2008), em empresas da Austrália e Reino Unido, encontraram resultados que indicam diminuição no nível de GR após a introdução do IFRS, países common-law, enquanto Jeanjean e Stolowy (2008) não obtiveram o mesmo resultado na França, país code-law, igualmente ao Brasil. Bonfim et al. (2016) 
demonstraram que a utilização das IFRS vem diminuindo o nível de suavização dos resultados para as seguradoras brasileiras. Percebe-se que a empresas do setor de construção brasileiras estão alinhados aos resultados de algumas pesquisas internacionais, demonstrando que, ainda que o brasil tenha característica de ser um país code-law, o setor oferece característica que diferenciam outros resultados já obtidos no Brasil.

Portanto, por se tratar de um setor específico e de peculiaridades especiais, percebe-se que as empresas desse setor tiveram seus níveis de gerenciamento de resultados reduzidos com o CPC 17, como observa-se no coeficiente da regressão (-.1659837). O IFRS 15 poderá impactar novamente este setor, trazendo mudanças na qualidade da informação contábil, visto que busca melhorar a comparabilidade e possíveis inconsistência nos critérios de reconhecimento de contratos (DANI et al., 2017). Essa nova realidade pode ser considerada como sugestão para as próximas pesquisas.

Além disso, o IFRS 15 permitirá maiores níveis de discricionariedade no reconhecimento de receitas e despesas, o que faz com que as escolhas contábeis das empresas reflitam o julgamento da administração, o que pode recair em atendimento de interesses particulares do próprio administrador ou organização (NIYAMA; RODRIGUES; RODRIGUES, 2015). Assim, a necessidade de já discutir sobre gerenciamento de resultados nessas empresas neste momento faz parte de uma discussão anterior à vigência desta norma, possibilitando discussões futuras, quando de sua vigência.

\section{CONSIDERAÇÕES FINAIS}

Este estudo objetivou verificar o comportamento das empresas brasileiras do setor de construção civil listadas na BM\&FBovespa em relação ao gerenciamento de resultados nos anos anteriores e posteriores à adoção do CPC 17. Devido alterações dos padrões internacionais na contabilidade advindos dos pronunciamentos contábeis CPC 17 e, em 2018, do CPC 47, torna-se pertinente olhar o comportamento passado para prever os impactos do novo padrão contábil.

Ao longo dos anos analisados, de 2007 a 2012, foi possível identificar que, em média, o Gerenciamento de Resultados foi decrescente e demonstra que o CPC 17 influenciou a gestão de resultados. Assim, de acordo com o modelo utilizado para a análise, os resultados evidenciaram que, após a vigência da norma, as organizações do setor de construção civil gerenciaram as suas acumulações discricionárias com o intuito de reduzir o seu lucro.

Ademais, da mesma forma que os resultados de Li, Chang e Xie (2013) com empresas de construção na China, observou-se que a prática de gerenciamento de resultados é negativa neste setor. Entretanto, o estudo aqui proposto avançou no sentido de não só verificar o comportamento do gerenciamento de resultados, mas também observar a influência que a padronização contábil trouxe para as práticas desta empresa.

Quanto à influência do CPC 17 sobre o Gerenciamento de Resultados, os achados deste estudo demonstram consistência estatística. As variáveis de controle ROA e TAM também foram capazes de explicar o gerenciamento de resultados. Além do mais, o CPC17, o ROA e o TAM tiveram impacto negativo na proporção que as empresas gerenciam os seus resultados. Assim, quanto maior o ROA e o TAM das empresas menor será o Gerenciamento de Resultados. Dessa forma, a adoção do CPC 17 foi um contra incentivo às práticas de gerenciamento de resultados destas empresas. Olhando para o contexto atual e futuro, o impacto da IRFS 15, conforme Dani et al. (2017) ressaltam, ainda há a necessidade de adequação ao IFRS 15, pois as mudanças relacionadas tanto no registro quanto no reconhecimento já estão sendo aceitas no âmbito do setor o que, possivelmente, vai afetar a informação divulgada por essas empresas.

Como contribuição este artigo ressalta que no primeiro ano após a implementação do CPC 17 também houve uma variação positiva no que tange ao gerenciamento de resultados. 
Porém, nos anos posteriores, foi perceptível que o comportamento de conservadorismo não só prevaleceu como se agravou. Logo, só é possível ter uma visão ampla do impacto da nova norma após o período de sua adoção, pois, assim como na adoção do CPC 17 (IAS 11), a adoção do CPC 47 (IRFS 15) pode no primeiro ano ter uma variação positiva, mas nos demais aos anos o comportamento ainda pode prevalecer.

Como limitações tem-se o fato de que outros setores podem apresentar resultados divergentes dos apresentados nesse estudo devido à questão do reconhecimento de receitas, que é uma dificuldade do setor. Também não realizou-se a análise do gerenciamento de resultados por atividades, o que poderia constatar diferentes resultados e conclusões. Para estudos posteriores, recomenda-se analisar o comportamento dos demais setores e o gerenciamento de resultados de acordo com o início da vigência de outros padrões internacionais implementados no Brasil.

\section{REFERÊNCIAS}

ALMEIDA, J. E. F.; ALMEIDA, J. C. G. Auditoria e earnings management: estudo empírico nas empresas abertas auditadas pelas big four e demais firmas de auditoria. Revista

Contabilidade \& Finanças-USP, v. 20, n. 50, p. 62-74, 2009.

ALMEIDA, D. M.; BEZERRA, F. A. Influência do fluxo de caixa operacional no gerenciamento de resultados em empresas da construção civil listadas na

BM\&FBovespa. Revista Base (Administração e Contabilidade) da UNISINOS, v. 9, $n$. 3 , p. 228-238, 2012.

BARBOSA, T. C. M.; SOUZA, C. A.; DALFIOR, V. A. O. Reconhecimento e evidenciação da receita e despesa por empresas da construção civil em conformidade com o CPC 17 Contratos de Construção. Anais do Simpósio de Excelência em Gestão e Tecnologia, Rio de Janeiro, RJ, Brasil, 12, 2015.

BARLEV, B.; HADDAD, J. R. Fair value accounting and the management of the firm. Critical Perspectives on Accounting, v. 14, n. 4, p. 383-415, 2003.

BARTH, M. E.; LANDSMAN, W. R.; LANG, M. H. International accounting standards and accounting quality. Journal of accounting research, v. 46, n. 3, p. 467-498, 2008.

BECKMAN, J.; KOCZAN, M. The FASBS Revenue Recognition Project: Pervasive Issues In Long-Term Contract Accounting. Construction Contract \& Taxation, v. 16, n. 4, p. 35-40, 2006.

BONFIM, M. P.; SILVA, J. P.; GONÇALVES, R. S.; SILVA, C. A. T. Adoção ao padrão IFRS e suavização dos resultados nas seguradoras brasileiras. Revista Universo Contábil, v. 12, n. 4, p. 152-171, 2016.

CALAZANS, W. G.; SOUZA, F. A. O Impacto da Lei 11.638/07 no Resultado das Empresas do Setor de Construção Civil Listadas na Bovespa. Anais do Congresso de Contabilidade e Controladoria, São Paulo, SP, Brasil, 12, 2012.

COELHO, A. C. D.; LOPES, A. B. Avaliação da prática de gerenciamento de resultados na apuração de lucro por companhias abertas brasileiras conforme seu grau de alavancagem financeira. Revista de Administração Contemporânea, v. 11, n. SPE2, p. 121-144, 2007. 
DANI, A. C.; SANTOS, C. A.; PANUCCI FILHO, L.; KLANN, R. C. Efeito da adoção antecipada da IFRS 15 na Qualidade da Informação Contábil. Revista Enfoque: Reflexão Contábil, v. 36, n. 2, p. 131-146, 2017.

DECHOW, P. M.; SKINNER, D. J. Earnings management: Reconciling the views of accounting academics, practitioners, and regulators. Accounting horizons, v. 14, n. 2, p. 235250,2000 .

ELBANNAN, M. A. Accounting and stock market effects of international accounting standards adoption in an emerging economy. Review of Quantitative Finance and Accounting, v. 36, n. 2, p. 207-245, 2011.

FALCÃO, D. F.; PINTO, L. J. S.; NIYAMA, J. K. Reconhecimento da receita de venda imobiliária: um estudo das maiores s/a's brasileiras no mercado residencial. Revista de Contabilidade do Mestrado em Ciências Contábeis da UERJ, v. 19, n. 1, p. 24-41, 2014.

FERREIRA, A. R.; THEÓPHILO, C. R. Contabilidade da construção civil: estudo sobre as formas de mensuração e reconhecimento de resultados. RIC-Revista de Informação Contábil, 1(1), 49-67, 2007.

FIELDS, T. D.; LYS, T. Z.; VINCENT, L. Empirical research on accounting choice. Journal of accounting and economics, v. 31, n. 1, p. 255-307, 2001.

FIRMINO, R. G.; ANDRADE, J. M. R. Análise da adoção das IFRS pelas companhias abertas brasileiras do setor de construção. Revista de Contabilidade da UFBA, v. 9, n. 3, p. 5-17, 2015.

HEALY, P. M.; WAHLEN, J. M. A review of the earnings management literature and its implications for standard setting. Accounting horizons, v. 13, n. 4, p. 365-383, 1999.

HEALY, P. M. The effect of bonus schemes on accounting decisions. Journal of accounting and economics, v. 7, n. 1-3, p. 85-107, 1985.

IATRIDIS, G. International Financial Reporting Standards and the quality of financial statement information. International review of financial analysis, v. 19, n. 3, p. 193-204, 2010 .

IATRIDIS, G.; ROUVOLIS, S. The post-adoption effects of the implementation of International Financial Reporting Standards in Greece. Journal of international accounting, auditing and taxation, v. 19, n. 1, p. 55-65, 2010.

JEANJEAN, T.; STOLOWY, H. Do accounting standards matter? An exploratory analysis of earnings management before and after IFRS adoption. Journal of accounting and public policy, v. 27, n. 6, p. 480-494, 2008.

JOIA, R. M.; NAKAO, S. H. Adoção de IFRS e gerenciamento de resultado nas empresas brasileiras de capital aberto. Revista de Educação e Pesquisa em Contabilidade (REPeC), v. 8, n. 1, 2014. 
GERENCIAMENTO DE RESULTADOS EM COMPANHIAS DO SETOR DE CONSTRUÇÃO CIVIL: INFLUÊNCIA DA ADOÇÃO DO CPC 17

KLANN, Roberto Carlos. Gerenciamento de resultados: análise comparativa de empresas brasileiras e inglesas antes e após a adoção das IFRS. 2011. 372 f. 2011. Tese de Doutorado. Tese (Doutorado em Ciências Contábeis e Administração)-Programa de PósGraduação em Ciências Contábeis da Universidade Regional de Blumenau, Blumenau.

KRISHNAN, G. V. Does Big 6 auditor industry expertise constrain earnings management?. Accounting horizons, v. 17, p. 1, 2003.

KANG, Sok-Hyon; SIVARAMAKRISHNAN, K. Issues in testing earnings management and an instrumental variable approach. Journal of accounting Research, p. 353-367, 1995.

LEUZ, C.; NANDA, D.; WYSOCKI, P. D. Earnings management and investor protection: an international comparison. Journal of financial economics, v. 69, n. 3, p. 505-527, 2003.

LI, C.; CHANG, Y.; XIE, Yufen. Empirical Study on Earnings Management of Listed Construction Enterprises in China. In: ICCREM 2013: Construction and Operation in the Context of Sustainability. 2013. p. 900-909.

LORENCINI, F. D.; COSTA, F. M. Escolhas contábeis no Brasil: identificação das características das companhias que optaram pela manutenção versus baixa dos saldos do ativo diferido/Accounting choices in Brazil: identifying the characteristics of publicly traded companies that opted to maintain versus derecognise deferred assets. Revista Contabilidade \& Finanças, v. 23, n. 58, p. 52, 2012.

MARCELLI, R. Gerenciamento de resultados em companhias brasileiras do setor da cons-trução civil. 105 f. Dissertação (Mestrado em Controladoria e Contabilidade) - FECAP - Faculdade Escola de Comércio Álvares Penteado, São Paulo, 2013.

MARTINEZ, A. L. Gerenciamento dos resultados contábeis: estudo empírico das companhias abertas brasileiras. 2001. Tese de Doutorado. Universidade de São Paulo.

MOTA, R. H. G.; VENTURA, A. F. A.; CUNHA, A. C.; PAULO, E. Adoção das Normas Internacionais de Contabilidade: Um estudo no setor de Construção Civil com ações listadas na BM\&FBOVESPA. Revista Ambiente Contabil, v. 7, n. 1, p. 1, 2015.

NASCIMENTO, H. J. A. Reconhecimento de receita e despesa em empresas de construção civil no Brasil: um estudo da aderência às normas contábeis. 2007. $151 \mathrm{f}$. Dissertação (Mestrado em Ciências Cont. Atuariais) - Pontifícia Universidade Católica de São Paulo, São Paulo, 2007.

NIYAMA, J. K.; CAVALCANTE, P. R. N.; REZENDE, I. C. C. Normas Contábeis Brasileiras, Norte-americanas e Internacionais aplicáveis ao setor de Construção Civil: uma análise comparativa numa empresa do Estado da Paraíba. In: IV Congresso ANPCont. 2010.

NIYAMA, J. K.; RODRIGUES, A. M. G.; RODRIGUES, J. M. Algumas reflexões sobre contabilidade criativa e as normas internacionais de contabilidade. Revista Universo Contábil, v. 11, n. 1, p. 69-87, 2015. 
PAULO, Edilson. Manipulação das informações contábeis: uma análise teórica e empírica sobre os modelos operacionais de detecção de gerenciamento de resultados. 2007. Tese de Doutorado. Universidade de São Paulo.

RICHARDSON, V. J. Information asymmetry and earnings management: Some evidence. Review of Quantitative Finance and Accounting, v. 15, n. 4, p. 325-347, 2000.

RICHARDSON, R. J. Pesquisa social: métodos e técnicas (3rd ed.). São Paulo: Atlas. 1999.

SANTIAGO, J. S.; CAVALCANTE, P. R. N.; PAULO, E. Análise da persistência e conservadorismo no processo de convergência internacional nas empresas de capital aberto do setor de construção no Brasil. Revista Universo Contábil, v. 11, n. 2, 2015.

SCHIPPER, Katherine. Commentary on earnings management. Accounting horizons, v. 3, n. 4, p. 91-102, 1989.

SILVA, M. Gerenciamento de resultados contábeis: estudo nas companhias abertas e fechadas do sul do Brasil. Dissertação de Mestrado em Ciências Contábeis, área de concentração Controladoria, Programa de Pós-Graduação em Ciências Contábeis, Universidade Regional de Blumenau, Santa Catarina, Blumenau, 2009.

VAN TENDELOO, B.; VANSTRAELEN, A. Earnings management under German GAAP versus IFRS. European Accounting Review, v. 14, n. 1, p. 155-180, 2005.

XU, G.; JI, X. Earnings management by top Chinese listed firms in response to the global financial crisis. International Journal of Accounting and Information Management, $v$. 24, n. 3, p. 226-251, 2016.

WOOLDRIDGE, Jeffrey M. Introductory econometrics: A modern approach. Nelson Education, 2003. 